\section{Molecular Syndromology}

Mol Syndromol 2017;8:225-226

DOI: $10.1159 / 000477230$
Accepted: March 29, 2017

by M. Schmid

Published online: June 9, 2017

\title{
Adding Insult to Injury, Complexity to Intricacy
}

In general, medical genetics tries to classify the phenotypes of a patient as manifestations of a syndrome; i.e., a correlated set of symptoms with a common cause. In genetic terms, this cause is supposed to be either "mendelian", "chromosomal", or de novo. Mendelian refers to a specific mode of transmission; e.g., recessive, dominant, or X-linked, of the disease allele(s) of a gene and the risk of recurrence of the disease within the family depending on the specific mode of transmission. Complex phenotypes that cannot be subsumed under a single gene are generally thought to be of "chromosomal" origin. This means that the organization of genomic elements, such as genes, promoters, enhancers, etc. has been altered such that a structural variation (SV) resulted [Poot and Haaf, 2015]. SVs may exert a phenotypic effect by changing the copy number of dosage-dependent genes leading to a loss or gain of one or several genes. In the latter case, a contiguous gene syndrome arises typified by a complex set of phenotypes consistent with several mendelian syndromes in a single patient. By comparison of patients with overlapping deletions, candidate genes within the contiguous gene syndrome can be pinpointed and their potential contribution to individual symptoms ascertained [Boland et al., 2007; Caliebe et al., 2010; Baliff et al., 2012; Depienne et al., 2017]. Second, an SV may disrupt the genomic architecture such that genes, parts of genes, and regulatory elements are relocated and their interactions perturbed. The phenotypic effects of the latter are mediated by alteration of gene expression patterns rather than changes in the structure of the encoded protein(s) [Reymond et al., 2007; Henrichsen et al., 2009; Klopocki and Mundlos, 2011; Lupiáñez et al., 2015; Spielmann and

\section{KARGER}

(C) 2017 S. Karger AG, Basel

E-Mail karger@karger.com

www.karger.com/msy
Mundlos, 2016]. Third, mixed mutational mechanisms in which CNVs, chromosome disruptions and gene mutations may occur simultaneously.

A particular type of mixed mutational mechanism, namely unmasking of a recessive disease allele by an overlapping loss in the other chromosome, known from studies of SVs, in particular CNVs, has recently been confirmed by diagnostic whole exome sequencing of a cohort of 2,076 patients [Flipsen-ten Berg et al., 2007; Hochstenbach et al., 2012; Poot and Haaf, 2015; Posey et al., 2017]. In 3 out of 101 patients exhibiting symptoms pertaining to 2 syndromes, homozygous intragenic deletions of 1-3 exons of a single gene were found [Posey et al., 2017]. This study shows that intragenic deletions may occur more often than thus far thought and highlights their relevance as a pathogenic mechanism [Poot, 2017; Posey et al., 2017]. These data are in agreement with the impression from a review of 27 literature reports that patients with "double syndromes" are more likely to harbor unmasking of recessive alleles than those with apparently random assortments of symptoms [Flipsen-ten Berg et al., 2007; Hochstenbach et al., 2012; Poot and Haaf, 2015; Posey et al., 2017].

Digenic disorders, such as retinitis pigmentosa, Bardet-Biedl and Joubert syndrome, some forms of deafness, some blood-clotting disorders, and Hirschprung disease, are well-known, while patients with dual or even multiple molecular diagnoses are rarely reported in the literature [Schäffer, 2013; Wallis et al., 2016]. In 101 cases out of 2,076 diagnostic whole exome sequencing (4.9\%), this underrecognized phenomenon has been documented [Posey et al., 2017]. The single nucleotide variants (SNVs)

Martin Poot

Department of Human Genetics, University of Würzburg Biozentrum, Am Hubland DE-97074 Würzburg (Germany)

E-Mail Martin_Poot@hotmail.com 
in those cases affected genes, showing recessive, dominant, or X-linked inheritance or any combination thereof. In the 42 patients with pathogenic SNVs in one or more autosomal recessive disease genes (53 SNVs in total), 28 variants, found in 20 patients, were inherited from their heterozygous parents [Posey et al., 2017]. These patients showed loss of heterozygosity involving multiple chromosomes, which contradicts uniparental disomy as a possible cause of homozygosity. In 12 out of these 101 patients, a combination of a SNV and a CNV contributed to the clinical phenotypes of the patient, which is less than found for CNVs alone in referral populations of patients with neurodevelopmental disorders [Hochstenbach et al., 2009, 2011; Posey et al., 2017].

The prevalence of patients with a double molecular diagnosis, $4.9 \%$, is much lower than expected. According to a Poisson model in which one assumes that pathogenic variants at different loci arise independently within each patient's genome, a prevalence of $14.0 \%$ would be expected. According to an independence model, based on the observed rate of single molecular diagnoses, a prevalence of $26.4 \%$ double molecular diagnosis would be expected. The authors attribute the significantly lower than expected prevalence of double molecular diagnosis in their study to the inherent ascertainment bias in referral populations. Nevertheless, this whole exome sequencing-based study reinforces the notion that a diagnostic evaluation is not complete with the identification of an initial molecular diagnosis and that genome-wide analyses are necessary to avoid "diagnostic fatalism" [Poot et al., 2011]. In cases in which 2 molecular diagnoses with 2 overlapping disease phenotypes were found, these should be considered as "double genetic diagnosis" instead of atypical extensions of a single mendelian disorder [Bartsch et al., 2012]. This study underscores the importance of the correct identification of such cases for counseling the families regarding the recurrence risk and for our understanding of the genomic architecture of complex human disease [Wallis et al., 2016; Posey et al., 2017].

Martin Poot

\section{References}

Ballif BC, Rosenfeld JA, Traylor R, Theisen A, Bader PI et al: High-resolution array CGH defines critical regions and candidate genes for microcephaly, abnormalities of the corpus callosum, and seizure phenotypes in patients with microdeletions of 1q43q44. Hum Genet 131:145-156 (2012).

Bartsch O, Schindler D, Beyer V, Gesk S, van't Slot $\mathrm{R}$, et al: A girl with an atypical form of ataxia telangiectasia and an additional de novo 3.14 $\mathrm{Mb}$ microduplication in region $19 \mathrm{q} 12$. Eur J Med Genet 55:49-55 (2012).

Boland E, Clayton-Smith J, Woo VG, McKee S, Manson FD, et al: Mapping of deletion and translocation breakpoints in 1q44 implicates the serine/threonine kinase AKT3 in postnatal microcephaly and agenesis of the corpus callosum. Am J Hum Genet 81:292-303 (2007).

Caliebe A, Kroes HY, van der Smagt JJ, MartinSubero JI, Tönnies H, et al: Four patients with speech delay, seizures and variable corpus callosum thickness sharing a $0.440 \mathrm{Mb}$ deletion in region 1q44 containing the HNRPU gene. Eur J Med Genet 53:179-185 (2010).

Depienne C, Nava C, Keren B, Heide S, Rastetter $\mathrm{A}$, et al: Genetic and phenotypic dissection of 1q43q44 microdeletion syndrome and neurodevelopmental phenotypes associated with mutations in ZBTB18 and HNRNPU. Hum Genet 136:463-479 (2017).
Flipsen-ten Berg K, van Hasselt PM, Eleveld MJ, van der Wijst SE, Hol FA, et al: Unmasking of a hemizygous WFS1 gene mutation by a chromosome $4 p$ deletion of $8.3 \mathrm{Mb}$ in a patient with Wolf-Hirschhorn syndrome. Eur J Hum Genet 15:1132-1138 (2007).

Henrichsen CN, Chaignat E, Reymond A: Copy number variants, diseases and gene expression. Hum Mol Genet 18:R1-8 (2009).

Hochstenbach R, van Binsbergen E, Engelen J, Nieuwint A, Polstra A, et al: Array analysis and karyotyping: workflow consequences based on a retrospective study of 36,325 patients with idiopathic developmental delay in the Netherlands. Eur J Med Genet 52:161-169 (2009).

Hochstenbach R, Buizer-Voskamp JE, Vorstman JA, Ophoff RA: Genome arrays for the detection of copy number variations in idiopathic mental retardation, idiopathic generalized epilepsy and neuropsychiatric disorders: lessons for diagnostic workflow and research. Cytogenet Genome Res 135:174-202 (2011).

Hochstenbach R, Poot M, Nijman IJ, Renkens I, Duran KJ, et al: Discovery of variants unmasked by hemizygous deletions. Eur J Hum Genet 20:748-753 (2012).

Klopocki E, Mundlos S: Copy-number variations, noncoding sequences, and human phenotypes. Annu Rev Genomics Hum Genet 12: 53-72 (2011).

Lupiáñez DG, Kraft K, Heinrich V, Krawitz P, Brancati F, et al: Disruptions of topological chromatin domains cause pathogenic rewiring of gene-enhancer interactions. Cell 161: 1012-1025 (2015).
Poot M: Intragenic CNTNAP2 deletions: a bridge too far? Mol Syndromol, 8:118-130 (2017).

Poot M, van der Smagt JJ, Brilstra EH, Bourgeron $\mathrm{T}$ : Disentangling the myriad genomics of complex disorders, specifically focusing on autism, epilepsy, and schizophrenia. Cytogenet Genome Res 135:228-240 (2011).

Poot M, Haaf T: Mechanisms of origin, phenotypic effects and diagnostic implications of complex chromosome rearrangements. Mol Syndromol 6:110-134 (2015).

Posey JE, Harel T, Liu P, Rosenfeld JA, James RA, et al: Resolution of disease phenotypes resulting from multilocus genomic variation. $\mathrm{N}$ Engl J Med 376:21-31 (2017).

Reymond A, Henrichsen CN, Harewood L, Merla G: Side effects of genome structural changes. Curr Opin Genet Dev 17:381-386 (2007).

Schäffer AA: Digenic inheritance in medical genetics. J Med Genet 50:641-652 (2013).

Spielmann M, Mundlos S: Looking beyond the genes: the role of non-coding variants in human disease. Hum Mol Genet 25:R157-165 (2016).

Wallis M, Tsurusaki Y, Burgess T, Borzi P, Matsumoto N, et al: Dual genetic diagnoses: atypical hand-foot-genital syndrome and developmental delay due to de novo mutations in HOXA13 and NRXN1. Am J Med Genet A 170:717-724 (2016). 